\title{
Dissolved and particulate nutrient transport in the Cheboksary Reservoir
}

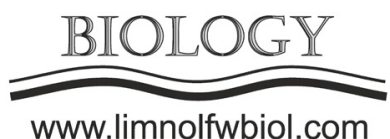

\author{
Tereshina M.*, Erina O., Sokolov D., Vilimovich E. \\ Lomonosov Moscow State University, GSP-1, Leninskie Gory, Moscow, 119991, Russia
}

\begin{abstract}
The reservoirs of the Middle and Lower Volga are prone to eutrophication due to an exceptionally large anthropogenic impact from agricultural, industrial and urbanized areas. To better understand the exact factors driving this process, it is necessary to have accurate data on the nutrient loading of the reservoirs, which comes mostly as river inflow, but there is very little information on the structure of the rivers' nutrient budget. Our summer field studies on a sector of the Cheboksary Reservoir from Nizhniy Novgorod to its lacustrine part in 2017-2019 provided a detailed picture of the dynamics of suspended and dissolved nitrogen and phosphorus and mineral silicon as the Volga River experiences significant hydrological and geochemical changes. The Oka River is shown be the primary supplier of nutrient elements into the reservoir which creates some distinct features of the nutrient regime of an over $100 \mathrm{~km}$ long part of the Volga cascade and contributes to a noticeable increase of the main river's nutrient load.
\end{abstract}

Keywords: reservoir water quality, eutrophication, nitrogen, phosphorus, particulate matter, dissolved matter

\section{Introduction}

The Cheboksary Reservoir is a unique freshwater system that receives most of its inflow via two distinct masses of water coming from the Oka and Volga river basins, both experiencing strong anthropogenic impact from some of the most densely populated and industrialized areas in Russia (Mineeva et al., 2008). The Volga River water is rich in humic organic matter because of a large portion of peat bog runoff, and much of its suspended load is retained in reservoirs upstream from Cheboksary, while the Oka River generally carries more dissolved and suspended solids and nutrient elements due to an unretained inflow from agricultural and urban areas. The mixing of these waters creates a specific environment for further biogeochemical processes, shaping the material flow of the Volga River downstream.

Research of the sources of nutrient pollution of the reservoir and transition between mineral and organic, dissolved and particulate forms of elements, may increase understanding of the factors driving the eutrophication of the Cheboksary Reservoir and other reservoirs of the Volga cascade (Maavara et al., 2015), and help to provide an accurate assessment of total nutrient load of the Middle Volga.

\section{Materials and methods}

In 2017-2019 we performed several summer field studies covering a sector of the Cheboksary Reservoir from Nizhniy Novgorod downward to the lacustrine part of the reservoir (100-220 km from the Oka and Volga confluence). We performed in-situ measurements of physical water properties (temperature, specific conductance, dissolved oxygen content) and collected water samples from right-side (Oka) and left-side (Volga) parts of the reservoir throughout the study area, subsequently determining concentrations of mineral and total phosphorus and total nitrogen in unfiltered and filtered $(0.45 \mu \mathrm{m})$ samples, and concentration of dissolved mineral silicon.

\section{Results and discussion}

In all three years of this study, the difference between the mineralization of the Oka and Volga rivers was 2-3 times and more, with specific conductance of the Oka River ranging from 520 to $670 \mu \mathrm{Sm} / \mathrm{cm}$ and the Volga River - from 195 to $220 \mu \mathrm{Sm} / \mathrm{cm}$. This difference was used to estimate the intensity of lateral mixing of the two streams: the left-side (Volga) and right-side (Oka) values of electric conductivity become close to equal (within 5-10\% difference) after a distance of over

*Corresponding author.

E-mail address: martereshina@yandex.ru (M. Tereshina)

(C) Author(s) 2020. This work is distributed under the Creative Commons Attribution 4.0 License. 
$90 \mathrm{~km}$ from Nizhniy Novgorod in 2017, over $120 \mathrm{~km}$ in 2018, and about $150 \mathrm{~km}$ in 2019, which indicates clear connection to the river discharge, which was the highest in 2017 and the lowest in 2019.

The vast difference between the Volga and Oka water chemistry is also displayed in their nutrient content. The Oka River consistently contains several times more total phosphorus and mineral silicon (TP 134-227 $\mu \mathrm{g} / \mathrm{L}$ in Oka versus 53-73 $\mu \mathrm{g} / \mathrm{L}$ in Volga at the confluence and Si $0.9-3.1 \mathrm{mg} / \mathrm{L}$ versus $0.5-1.8 \mathrm{mg} / \mathrm{L}$ ), and slightly more total nitrogen (TN $1.2 \mathrm{mg} / \mathrm{L}$ in Oka versus $0.8-1.1 \mathrm{mg} / \mathrm{L}$ in Volga). For nutrient elements, the difference between the right-side and left-side concentrations is smoothed out over a shorter distance than observed for mineralization - in about $85 \mathrm{~km}$ : the TP value reaches about $80-100 \mu \mathrm{g} / \mathrm{L}, \mathrm{TN}-1.0 \mathrm{mg} / \mathrm{L}$, $\mathrm{Si}$ - about 1.4-2 mg/L.

A larger portion of Volga's phosphorus and nitrogen (up to $70 \%$ compared to about $50 \%$ in the Oka) is presented in dissolved form, which can be explained by retention of a significant part of suspended particles (both mineral and living organisms) in the upper Volga reservoirs. During the first 15 to $25 \mathrm{~km}$ after the two rivers meet, the total and particulate phosphorus concentrations in the Oka stream decline and the TDP/TP ratio reaches $60-85 \%$, while the left-side water composition is barely changed, which suggests deposition of some of the Oka River's solid particles into sediment.

It is important that only a very scarce amount of dissolved inorganic phosphorus is available both in Volga and Oka, and a slight additional influx of phosphate is supplied only after the river flows through the Nizhniy Novgorod city and receives some municipal wastewater. In 2019, the total dissolved phosphorus concentration below the wastewater treatment plant reached almost $40 \mu \mathrm{g} / \mathrm{L}$ at the right side and remained below $5 \mu \mathrm{g} / \mathrm{L}$ at the left side of the river. Over the next $80-120 \mathrm{~km}$, the diffusion of inorganic nutrients throughout the cross-section of the river and a decline in flow velocity act as a boost for phytoplankton growth: the DIP concentration drop to under $10 \mu \mathrm{g} / \mathrm{L}$ again, and the chlorophyll concentrations rise at both sides of the river.

\section{Conclusions}

It is apparent that the Oka River can be pointed out as a major source of nutrient pollution of the Cheboksary Reservoir, as its inflow eventually causes a steady increase in the nutrient budget of the freeflowing Volga part of the reservoir. The change in hydrodynamics of the joined Oka and Volga streams causes some of its suspended load to be lost to sediment deposition, but a major part of the original nutrient loading of the two rivers follows downstream, increasing total nitrogen and phosphorus concentrations in the Volga River as the two water masses mix together.

\section{Acknowledgments}

Most of the fieldwork for this study was supported by the Russian Geographical Society ("the Floating University of the Volga Basin" project). Data processing and analysis was funded by the Russian Foundation for Basic Research (project No. 19-05-50109).

\section{References}

Maavara T., Parsons C.T., Ridenoir C. et al. 2015. Global phosphorus retention by river damming. Proceedings of the National Academy of Sciences 112: 15603-15608. DOI: 10.1073/pnas.1511797112

Mineeva N.M., Litvinov A.S., Stepanova I.E. et al. 2008. Chlorophyll content and factors affecting its spatial distribution in the Middle Volga reservoirs. Inland Water Biology 1: 64-72. DOI: 10.1007/s12212-008-1010-5 